\title{
Abnormal urinary excretion of NKCC2 and AQP2 in response to hypertonic saline in chronic kidney disease: an intervention study in patients with chronic kidney disease and healthy controls
}

\author{
Janni M Jensen ${ }^{1,2^{*}}$, Frank H Mose ${ }^{1,2}$, Anna-Ewa O Kulik ${ }^{1,2}$, Jesper N Bech ${ }^{1,2}$, Robert A Fenton ${ }^{3}$
} and Erling B Pedersen ${ }^{1,2}$

\begin{abstract}
Background: Renal handling of sodium and water is abnormal in chronic kidney disease (CKD). The aim of this study was to test the hypothesis that abnormal activity of the aquaporin-2 water channels (AQP2), the sodium-potassium-2chloride transporter (NKCC2) and/or the epithelial sodium channels (ENaC) contribute to this phenomenon.

Methods: 23 patients with CKD and 24 healthy controls at baseline and after 3\% saline infusion were compared. The following measurements were performed: urinary concentrations of AQP2 (u-AQP2), NKCC2 (u-NKCC2), ENaC (u-ENaCY), glomerular filtration rate (GFR) estimated by ${ }^{51} \mathrm{Cr}$-EDTA clearance, free water clearance $\left(\mathrm{C}_{\mathrm{H} 2 \mathrm{O}}\right)$, urinary output (UO), fractional excretion of sodium ( $F E_{N a}$ ), plasma concentrations of AVP, renin (PRC), Angiotensin II (ANG II), Aldosterone (Aldo) and body fluid volumes.

Results: At baseline, GFR was $34 \mathrm{ml} / \mathrm{min}$ in CKD patients and $89 \mathrm{ml} / \mathrm{ml}$ in controls. There were no significant differences in $\mathrm{u}-\mathrm{AQP2}$, $\mathrm{u}-\mathrm{NKCC2}$ or $\mathrm{u}-\mathrm{ENaC}$, but $\mathrm{FE}_{\mathrm{Na}}$, $\mathrm{p}$-Aldo and p-AVP were higher in CKD patients than controls. In response to hypertonic saline, patients with $C K D$ had an attenuated decrease in $\mathrm{C}_{\mathrm{H} 2 \mathrm{O}}$ and $\mathrm{UO}$. A greater increase in U-AQP2 was observed in CKD patients compared to controls. Furthermore, u-NKCC2 increased in CKD patients, whereas U-NKCC2 decreased in controls. Body fluid volumes did not significantly differ.
\end{abstract}

Conclusions: In response to hypertonic saline, u-NKCC2 increased, suggesting an increased sodium reabsorption via NKCC2 in patients with CKD. U-AQP2 increased more in CKD patients, despite an attenuated decrease in $\mathrm{C}_{\mathrm{H} 2 \mathrm{O}}$. Thus, though high levels of p-AVP and p-Aldo, the kidneys can only partly compensate and counteract acute volume expansion due to a defective tubular response.

Trial registration: Clinical trial no: NCT01623661. Date of trial registration: 18.06.2012.

Keywords: Chronic kidney disease, NKCC2, AQP2, ENaC, Sodium, Water

\footnotetext{
* Correspondence: jannimaj@gmail.com

'Department of Medical Research, Holstebro Hospital, University Clinic in Nephrology and Hypertension, Laegaardvej 12, 7500 Holstebro, Denmark ${ }^{2}$ Regional Hospital Jutland West and Aarhus University, Aarhus, Denmark Full list of author information is available at the end of the article
} 


\section{Background}

In chronic kidney disease (CKD), total renal mass is reduced and single nephron glomerular filtration rate increases in the remaining nephrons [1]. This hyper filtration, accompanied by a compensatory renal hypertrophy, are associated with alterations in tubular absorptive capacities of sodium and water that ultimately leads to an impaired ability to concentrate urine [2,3]. Animal studies have demonstrated that compared to healthy control animals, aquaporin-2 water channels (AQP2) and various sodium transporters are differentially expressed in rats with chronic renal failure (CRF) [4]. Furthermore, AQP2 has been linked to numerous conditions with disturbed water balance, including CKD [5-9]. Mutations in sodium transporters and their regulatory factors have been linked to disturbances in sodium homeostasis and blood pressure [10-12]. However, there is little knowledge of the involvement of these proteins in the defective urine concentrating mechanism in patients with CKD.

Quantification of the urinary excretion of the sodiumpotassium-2-chloride cotransporter (NKCC2), AQP2 and the epithelial sodium channels $(\mathrm{ENaC})$, as an estimate of their tubular abundance and thus their function, may provide important information regarding a dysfunctional transport activity in CKD [13-15]. Therefore, in the present study we performed an intervention study in patients with CKD stage III-IV and healthy control subjects during baseline conditions and in response to an acute 3\% hypertonic saline infusion to test the following hypothesis; 1) the tubular handling of sodium and water is different in patients with CKD compared to healthy subjects and 2) Different sodium and water handling by the kidney is reflected by varying changes in urinary excretion of AQP2, NKCC2 and/or ENaC. Our study documents that in both healthy subjects and patients with CKD there are changes in $\mathrm{u}-\mathrm{NKCC} 2$, in response to a hypertonic saline load.

\section{Methods \\ Design}

The study was conducted as an intervention study with a case group, consisting of patients with CKD, and a healthy control group. The CKD patients were matched with healthy controls one to one according to gender and age. An age discrepancy of three years was accepted.

\section{Recruitment}

Patients with CKD were recruited from the Outpatient Clinic of Nephrology and Hypertension, Holstebro, Regional Hospital Jutland West. Healthy participants were recruited by advertisements in local newspapers, in the area of Holstebro, Denmark.

\section{Study settings}

The study took place at Dept. of Medical Research, University Clinic of Nephrology and Hypertension, Regional Hospital Holstebro, Denmark, from $1^{\text {st }}$ of October 2011 until 1 $^{\text {st }}$ of May 2013.

\section{Participants \\ CKD Patients}

The inclusion criteria for patients were: men and women; aged between 18 and 70 years; body mass index $(\mathrm{BMI}) \leq 32 \mathrm{~kg} / \mathrm{m}^{2}$; a diagnosis of CKD and estimated GFR (e-GFR) between $15-60 \mathrm{ml} / \mathrm{min}$ i.e. CKD stage IIIIV. The exclusion criteria were: heart failure; pulmonary-, liver-, endocrine-, cerebral or malignant disease; immunosuppressive treatment; alcohol abuse (more than 21 alcoholic drinks per week for males and 14 drinks for females); difficulty in urinating; medicine abuse; currently smoking; pregnancy; unwillingness to participate. Withdrawal criteria: Development of one or more of the conditions given in 'exclusion criteria' during the course of the study; withdrawal of informed consent; poor compliance; problems with blood or urine sampling.

\section{Healthy control subjects}

The inclusion criteria for healthy controls were: men and women; aged between $18-70$ years; $\mathrm{BMI} \leq 32 \mathrm{~kg} / \mathrm{m}^{2}$. The exclusion criteria were: clinical signs or history of heart-, pulmonary-, kidney-, cerebral-, endocrine or malignant diseases; abnormal findings in ECG, urine dipstick or biochemistry (blood cell count, b-hemoglobin, plasma concentrations of sodium, potassium, creatinine, albumin, glucose, bilirubin, alanine aminotransferase, alkaline phosphatase and cholesterol); arterial hypertension (24 hourambulatory blood pressure $>130 / 80 \mathrm{mmHg}$ ); medical treatment (except oral contraceptives); alcohol abuse (more than 21 alcoholic drinks per week for males and 14 drinks for females); substance abuse; current smoking; pregnancy; breast feeding; donation of blood within one month prior to the study; unwillingness to participate. The withdrawal criteria: Development of one or more of the conditions given in exclusion criteria during the course of the experiment; withdrawal of informed consent; poor compliance; problems with blood or urine sampling.

\section{Ethics}

This study was approved by the Regional Committee on Health Research Ethics (j. no. M-20110131) and carried out in accordance with the Helsinki Declaration. Written informed consent was obtained from all subjects.

\section{Effect variables}

The main effect variable was $\mathrm{u}-\mathrm{NKCC} 2$. Other effect variables were: $\mathrm{u}-\mathrm{AQP} 2, \mathrm{u}-\mathrm{ENaC} \gamma$, glomerular filtration rate $(\mathrm{GFR})$, free water clearance $\left(\mathrm{C}_{\mathrm{H} 2 \mathrm{O}}\right)$, urine output 
(UO), fractional excretion of sodium $\left(\mathrm{FE}_{\mathrm{Na}}\right)$ and potassium $\left(\mathrm{FE}_{\mathrm{K}}\right)$, urine osmolality (u-osm), plasma sodium ( $\left.\mathrm{p}-\mathrm{Na}\right)$, plasma osmolality (p-osm), plasma concentration of renin (PRC), angiotensin II (AngII), aldosterone (Aldo), vasopressin (AVP), extracellular fluid volume (ECV), intracellular fluid volume (ICV) and total body water (TBW).

\section{Number of subjects}

Using a significance level of $5 \%$ and a power of $80 \%$ it was calculated that the number of subjects needed in both groups was 16 , when the minimal relevant difference in $\mathrm{u}-\mathrm{NKCC} 2$ was $0.3 \mathrm{ng} / \mathrm{min}$ and SD was $0.3 \mathrm{ng} / \mathrm{min}$. In this study, incomplete voiding during study days was expected in some subjects; therefore a minimum of 20 subjects was included in each group.

\section{Experimental procedures}

\section{Experimental procedure prior to the study day}

Four days prior to each study day, subjects consumed a standardized diet regarding calories, sodium and fluid. The diet consisted of 11,000 (kJ/day) with an energy distribution of $55 \%$ carbohydrates, $30 \%$ fat and $15 \%$ protein in accordance to general dietary guidelines. The sodium content was 130-150 mmol pr. day. The subjects were asked to drink $2500 \mathrm{ml} /$ day. No alcohol or soft drink consumption was allowed while on the standardized diet. A maximum of two cups $(6 \mathrm{oz}$.) of coffee or tea was allowed daily. Subjects were instructed to keep their usual physical activity during the experiments but to abstain from hard training the day prior to the examination. CKD patients followed their normal medical prescriptions during the four-day-diet period, but not on the morning of the study day. A 24-hour urine collection, ending at 7:00 AM on the examination-day, was used to assess water and sodium balance.

\section{Experimental procedure on the study day}

Following an overnight fast, subjects arrived at the study facility at 8:00 AM. Two indwelling catheters for blood sampling and administration of ${ }^{51} \mathrm{Cr}$-EDTA and saline were placed in both cubital veins. Every 30 minutes starting at arrival, participants received a $175 \mathrm{ml}$ oral water load of tap water. Urine was collected in standing or sitting position. Otherwise, subjects were kept in the supine position in a quiet temperature-controlled room $\left(22-25^{\circ} \mathrm{C}\right)$. At 9:00 AM a priming dose of ${ }^{51} \mathrm{Cr}$-EDTA was administered, followed by sustained infusion. Three 30-minute baseline clearance periods were obtained from 9:30 AM to 11:00 AM (time: 0-90 min). These were followed by one clearance period from 11:00 AM to 12:00 PM (time: 90-150 min) during which a sustained infusion of $3 \%$ hypertonic saline was administered. The post infusion period consisted of three 30 -minute periods from 12:00 PM to 1:30 PM (time: $150-240 \mathrm{~min}$ ).

Blood and urine samples were collected every 30 minutes from 8:30 AM to 1:30 PM. Blood samples were drawn and analyzed for ${ }^{51} \mathrm{Cr}$-EDTA, p-sodium, p-potassium, p-albumin and p-osmolality. Analysis of PRC, p-Ang II, p-Aldo and p-AVP were conducted from blood samples drawn at 11:00 AM, 12:00 PM and 1:30 PM.

Urine samples were analyzed for $u-{ }^{51} \mathrm{Cr}$-EDTA, $\mathrm{u}$-sodium, u-potassium, u-creatinine and u-osmolality. Analysis of u-AQP2, u-NKCC2 and $\mathrm{u}-\mathrm{ENaC} \gamma$ was conducted from the 24-h urine collection and clearance period 10:30-11:00 AM (basal); 11:00-12:00 AM (cessation of fluid infusion), 12:00-12:30 PM (30 min after cessation of fluid infusion) and 1:00-1:30 PM (90 min after cessation of fluid infusion). For data analysis, the 30-minute periods from 9:30 AM to 1:30 PM were subdivided into: baseline (0-90 min), infusion period (90-150 $\mathrm{min})$ and post infusion period (1:150-180 $\mathrm{min}$, 2:180-210 $\mathrm{min}$ and 3: 210-240 $\mathrm{min}$ ).

Body composition was measured at 8:30 AM (arrival), 11:00 AM (before infusion), 12:00 PM (after infusion) and 1:30 PM (end of examination day).

\section{Measurements \\ Renal function}

Glomerular filtration rate was measured by the constant infusion clearance technique with ${ }^{51} \mathrm{Cr}$-EDTA as reference substance. More than $15 \%$ variation in GFR between the three baseline periods led to the exclusion of analysis.

\section{Calculations}

Fractional excretion of sodium and potassium was calculated as: [Sodium/potassium clearance $\left(C_{\mathrm{Na} / \mathrm{K}}\right) / \mathrm{GFR} \times$ $100 \%$ ]. Free water clearance was calculated as: [Urine output (UO) - osmolar clearance $\left.\left(C_{\mathrm{OMS}}\right)\right]$. $C_{\mathrm{OSM}}$ was calculated as: [Urine osmolarity/plasma osmolarity $\times$ $\mathrm{UO}$.

\section{Blood samples}

Were centrifuged for 10 minutes at $2200 \times \mathrm{g}$ at $4^{\circ} \mathrm{C}$. Plasma hormone samples were kept frozen at $-20^{\circ} \mathrm{C}$ (AngII) and $-80^{\circ} \mathrm{C}$ (PRC, Aldo, and AVP) until assayed. Renin in plasma was determined using an immunoradiometric assay (CIS Bio International, Gif-Sur-Yvette Cedex, France). Minimal detection level was 1 pg./mL the coefficients of variation were $14.5 \%$ (interassay) and $4.5 \%$ (intra assay). Aldosterone in plasma was determined by radioimmunoassay (Demeditec Diagnostics Systems Laboratories Inc.,Webster, TX, USA). Minimal detection level was $22 \mathrm{pmol} / \mathrm{L}$. The coefficients of variation were $8.2 \%$ (inter-assay) and 3.9\% (intra-assay). Arginine vasopressin and Angiotensin II were extracted from 
plasma with $\mathrm{C}_{18}$ Sep-Pak (Water associates, Milford, MA, USA) and subsequently measured using radioimmunoassay as previously described [16]. The antibody against angiotensin II was obtained from the Department of Clinical Physiology, Glostrup Hospital, Glostrup, Denmark. Minimal detection level was $2 \mathrm{pmol} / \mathrm{L}$. The coefficients of variation were $12 \%$ (inter-assay) and $8 \%$ (intra-assay). The antibody against AVP was a gift from Professor Jacques Dürr (Miami, FL, USA). Minimal detection level was $0.2 \mathrm{pmol} / \mathrm{L}$. The coefficients of variation were $13 \%$ (inter-assay) and $9 \%$ (intra -assay).

\section{Generation of NKCC2 specific antibody}

A novel rabbit polyclonal antiserum against human NKCC2 (Slc12a2) was generated against the following peptide: CNITKTTPKKDGSIN by Genscript ${ }^{\ominus}$ (New Jersey, USA). The N-terminal cysteine was added for conjugation to carrier protein and for attaching the peptide to the affinity purification column. The immune serum from two rabbits (\#593 and \#594) was affinity purified using immunizing peptides, resulting in NKCC2-specific antibodies.

\section{Urine sample immunoassays}

Urines were stored frozen at $-20^{\circ} \mathrm{C}$ until assayed.

U-NKCC2 was measured in urine by a newly developed radioimmunoassay. Iodination of the NKCC2 peptide was performed by the chloramine $\mathrm{T}$ method using $40 \mu \mathrm{g}$ of $98 \%$ pure NKCC2 peptide and $37 \mathrm{MBq}{ }^{125} \mathrm{I}$. The reaction was stopped by the addition of $20 \%$ human serum albumin. ${ }^{125}$ I-labelled NKCC2 was separated from the iodination mixture by the use of a Sephadex G-25 Fine column. The assay buffer was $40 \mathrm{mM}$ sodium phosphate $(\mathrm{pH}=7.4), 0.2 \%$ human albumin, $0.1 \%$ Triton $\mathrm{X}-100$ and $0.4 \%$ EDTA. A $1.5 \%$ solution of bovine gamma globulins (USB corporation, Cleveland, OH, USA) and 25\% polyethylene glycol 6000 (Merck) also containing 0.625\% Tween 20 (Merck) was prepared using the $40 \mathrm{mM}$ phosphate buffer. After thawing, urine samples were centrifuged for $10 \mathrm{~min}$ at $2200 \mathrm{~g}(3500 \mathrm{rpm})$. A quantity of the supernatant containing $300 \mathrm{mosmol} / \mathrm{l}$ was freeze dried and stored at $-20^{\circ} \mathrm{C}$ until assayed. Standards or freezedried urine samples were dissolved in $300 \mu \mathrm{L}$ assay buffer with $0.2 \%$ human albumin, $50 \mu \mathrm{L}$ of antibody was added, and the mixture was incubated for $24 \mathrm{~h}$ at $4^{\circ} \mathrm{C}$. Thereafter, $50 \mu \mathrm{L}$ of the tracer were added, and the mixture was incubated for a further $24 \mathrm{~h}$ at $4^{\circ} \mathrm{C}$. Bovine gamma globulin $(100 \mu \mathrm{L})$ and $2 \mathrm{~mL}$ polyethylene glycol 6000 were added. The mixture was centrifuged at $3500 \mathrm{rpm}$ for $20 \mathrm{~min}$ at $4^{\circ} \mathrm{C}$. The supernatant (free fraction) was poured off, and the precipitate (bound fraction) was counted in a gamma counter. The unknown content in urine extracts was read from a standard curve. For 9 consecutive standard curves, the zero standard was $35 \pm 4.7 \%$, and for increasing amounts of NKCC2 standard, the binding inhibition was: $33 \pm 4.7 \%$ (0.0625 ng/tube), $32 \pm 4.4 \%$ (0.125 ng/tube), $29 \pm 3.9 \%$ (0.25 ng/tube), $25 \pm 3.4 \%$ (0.5 ng/tube), $20 \pm 2.8 \%$ (1.0 ng/tube), $15 \pm 1.8 \%$ (2.0 ng/ tube), $12 \pm 1.5 \%$ (4.0 ng/tube), $10 \pm 1.4 \%$ ( $8.0 \mathrm{ng} /$ tube). The ID 50, i.e. the concentration of standard needed for $50 \%$ binding inhibition, was $1.37 \pm 0.14 \mathrm{ng} /$ tube $(\mathrm{n}=9)$. Non-specific binding, determined by performing the RIA without antibody, was $6.7 \pm 1.2 \%(\mathrm{n}=9)$.

Inter-assay variation was determined by quality controls from the same urine pool spiked with NKCC2 standard. In consecutive assays, the coefficient of variation was: at a mean level of $0.286 \mathrm{ng} /$ tube $16 \%$ ( 14 assays), at a mean level of $0.736 \mathrm{ng} /$ tube $12 \%$ (18 assays), at a mean level of $2.16 \mathrm{ng} /$ tube $13 \%$ (15 assays), and at a mean level of $4.51 \mathrm{ng} /$ tube $15 \%$ (14 assays).

Intra-assay variation was determined on samples from the same urine pool in several assays at different concentration levels. At a mean level of $0.126 \mathrm{ng} /$ tube $(\mathrm{n}=10)$ and $0.309 \mathrm{ng} /$ tube $(\mathrm{n}=10)$, the coefficients of variation were $7.5 \%$ and $6.0 \%$, respectively. In addition, the coefficients of variation were calculated on the basis of duplicate determinations in different assays to $2.0 \%(\mathrm{n}=14)$ in the range $0.286-0.320 \mathrm{ng} / \mathrm{tube}, 5.9 \%(\mathrm{n}=18)$ in the range $0.731-0.736 \mathrm{ng} / \mathrm{tube}, 7.0 \%(\mathrm{n}=15)$ in the range $0.216-0.217 \mathrm{ng} /$ tube, $7.3 \%(\mathrm{n}=14)$ in the range 0.451 $0.468 \mathrm{ng} / \mathrm{tube}$, and $1.3 \%(\mathrm{n}=61)$ in the whole range 0.286-0.468 ng/tube.

Sensitivity calculated as the smallest detectable difference at the $95 \%$ confidence limit was $0.71 \mathrm{ng} /$ tube in the range $0.286-0.320 \mathrm{pg} /$ tube $(\mathrm{n}=14), 0.13 \mathrm{ng} / \mathrm{tube}$ in the range $0.731-0.735 \mathrm{ng} /$ tube $(\mathrm{n}=18), 0.44 \mathrm{ng} /$ tube in the range $2.16-2.17 \mathrm{ng} /$ tube $(\mathrm{n}=15), 1.04 \mathrm{ng} /$ tube in the range 4.51-4.68 ng/tube ( $\mathrm{n}=14)$ and $2.35 \mathrm{ng} /$ tube in the whole range $0.29-4.68 \mathrm{ng} /$ tube $(\mathrm{n}=61)$. The lower detectable limit of the assay was $0.5 \mathrm{ng} /$ tube. It was calculated using the average zero binding for 9 consecutive assays minus $2 \mathrm{SD}$. The volume of urine used for extraction from the same pool was varied (17 different volumes in the range $250-5000 \mu \mathrm{l}$ ), and the mean concentration measured was $0.463 \pm 0.066 \mathrm{ng} / \mathrm{ml}$. There was a highly significant correlation between the extracted volume of urine and the amount of ng/tube $(\mathrm{r}=0.979, \mathrm{n}=17, \mathrm{p}<0.000)$. When NKCC2 in the range of 0.37-2.38 ng was added to urine, a significant correlation was found between the measured and the expected values $(r=0.896, n=9$, $\mathrm{P}<0.001)$.

U-AQP2 was measured by radioimmunoassay as previously described $[17,18]$. Antibodies were raised in rabbits to a synthetic peptide corresponding to the 15 $\mathrm{COOH}$-terminal amino acids in human AQP2 to which was added an $\mathrm{NH}_{2}$-terminal cysteine for conjugation and affinity purification. Minimal detection 
level was $34 \mathrm{pg} /$ tube /tube. The coefficients of variation were $11.7 \%$ (inter-assay) and 5.9\% (intra-assay).

$\mathrm{U}-\mathrm{ENaC} \gamma$ was measured by radioimmunoassay as previously described $[19,20]$. Antibodies were raised against a synthetic $\mathrm{ENaC} \gamma$ peptide in rabbits and affinity purified [21]. Minimal detection level was 48 pg/tube. The coefficients of variation were $14 \%$ (inter-assay) and $6.7 \%$ (intra-assay).

\section{Blood pressure measurement}

Brachial blood pressure was recorded using a semiautomatic oscillometric device (Omron 705IT, Omron Matsusaka, Japan)

\section{Plasma and urine}

Concentrations of sodium, potassium, creatinine and albumin were measured using routine methods at the Department of Clinical Biochemistry, Holstebro Hospital.

\section{Bioimpedance spectroscopy}

Was performed at 50 frequencies, from 5 to $1000 \mathrm{kHz}$ using the Fresenius Body Composition Monitor and the Fluid Management Tool, version 3.

\section{Statistics}

Statistical analyses were performed using IBM SPSS statistics version 20.0.0 (IBM Corp.; Armonk, NY, USA). Single baseline values were obtained by taking the weighed average of the measurements from the three baseline periods. Parametric data are presented as means \pm standard deviation (SD) and nonparametric data as medians with 25th and 75th percentiles in brackets. General linear model with repeated measures (GLM RM) was performed for comparison with time as within-subject factor and group as between-subject factor, to test for differences within and between groups. Independent samples t-test or Mann-Whitney $U$ test were used for comparison of CKD patients vs. controls and CKD patients stage IV vs. CKD stage III. Paired t-test or related samples Wilcoxon Signed Rank test were used to compare baseline within groups to the following periods. Statistical significance was defined as $\mathrm{p}<0.05$ in all analyses.

\section{Results}

\section{Demographics}

\section{CKD Patients}

Patients in the Outpatient Clinic were consecutively screened for participants to the study. Twenty-seven CKD patients were included in the study. Four patients withdrew consent. Thus, 23 CKD patients were initially allocated to, and completed the study. Three patients were not able to void satisfactorily during clearance experiments and were excluded from urine analyses (Figure 1).
The primary renal disease was nephrosclerosis due to essential hypertension ( $\mathrm{n}=7$ ), chronic glomerulonephritis $(n=3)$, adult polycystic kidney disease $(n=3)$, interstitial nephropathy $(\mathrm{n}=1)$, systemic sclerosis $(\mathrm{n}=1)$ and unknown nephropathy $(\mathrm{n}=8)$. All CKD patients received antihypertensive treatment in various combinations i.e. angiotensin converting enzyme inhibitor $(n=12)$, calcium channel antagonists $(n=12)$, loop diuretics $(n=11)$, beta-adrenergic blockers $(n=9)$, thiazides $(n=7)$, angiotensin II receptor antagonists $(n=6)$, potassium sparing diuretics $(\mathrm{n}=1)$ and minoxidil $(\mathrm{n}=1)$.

\section{Healthy controls}

A total of 32 subjects were screened to enter the study, but eight subjects were withdrawn due to arterial hypertension. Thus, 24 healthy controls were initially allocated to and completed the study. Three subjects were not able to void satisfactorily during clearance experiments and were excluded from urine analysis only (Figure 1).

Baseline characteristics are shown in Table 1. Values were similar between the two groups with the exception of plasma creatinine (p-Crea), eGFR, plasma urea, urine albumin (u-Alb), p-potassium and p-hemoglobin.

\section{NKCC2 antibody characterization}

The affinity-purified antibodies were utilized for western blotting of human kidney samples using standard procedures. Both antibodies detected a glycosylated smear of approximately $170 \mathrm{kDa}$ representing NKCC2 in cortex and medulla (Figure 2A), but no signal in a rat inner medulla protein sample. The specific protein bands were not observed following pre-incubation of the antibody with the immunizing peptide. Immunohistochemistry of human kidney sections demonstrated strong labeling at the apical pole of thick ascending limb cells (Figure 2B,C). No labeling of similar sections was detected following pre-incubation of the antibody with the immunizing peptide (not shown).

\section{Twenty-four-hour urine collection}

Table 1 shows the results of the 24-h urine collection. Mean u-AQP2, u-NKCC2, u-ENaC $\gamma$, urinary sodium-, potassium-, osmolarity- and volume did not differ significantly. Controls had a small, but significantly more negative $\mathrm{C}_{\mathrm{H} 2 \mathrm{O}}$ and higher creatinine clearance than patients with CKD. Both $\mathrm{FE}_{\mathrm{Na}}$ and $\mathrm{FE}_{\mathrm{K}}$ were significantly higher in the CKD patient group. No significant differences in u-NKCC2 were detected between patients treated with furosemide vs. no-furosemide in 24-h urine collection (406 ng/mmol \pm 108 vs. $357 \pm 92 ; \mathrm{p}=0.293$ ) or during the examination day (data not shown). 


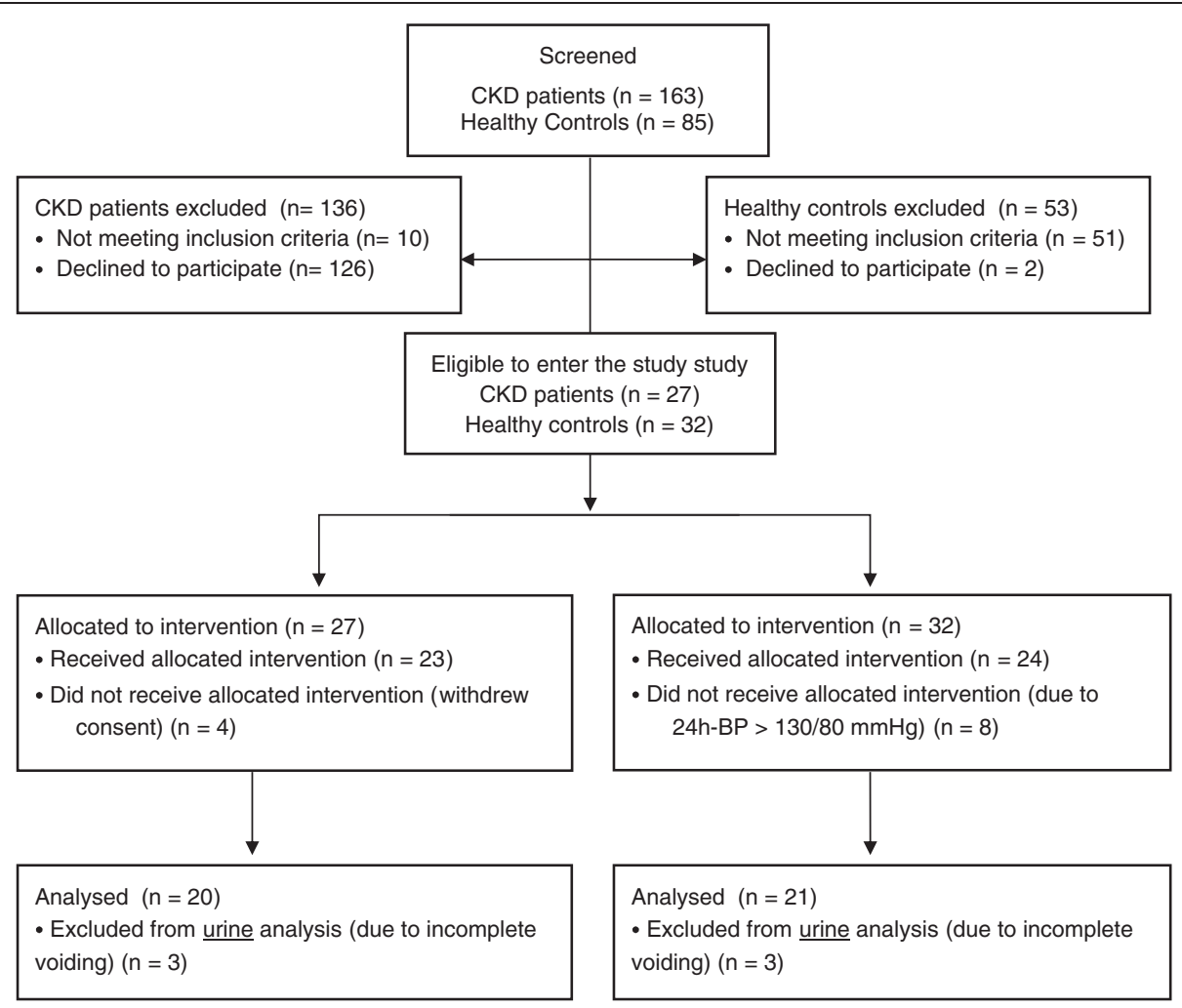

Figure 1 CONSORT flow chart over the participant flow through screening, inclusion and analysis.

\section{Excretion of water and $u-A Q P 2$, urine osmolality and GFR}

Figure $3 \mathrm{~A}$ shows the changes in $\mathrm{u}-\mathrm{AQP} 2$, Figure 4A-D the changes in, UO, $\mathrm{u}$-osm, $\mathrm{C}_{\mathrm{H} 2 \mathrm{O}}$ and GFR.

There was no difference in $\mathrm{u}-\mathrm{AQP} 2$ at baseline (Figure 3A). At the end of hypertonic saline infusion, $\mathrm{u}-\mathrm{AQP} 2$ increased significantly in CKD patients but not in controls. During the post infusion periods, $\mathrm{u}-\mathrm{AQP} 2$ gradually increased in controls, whereas $\mathrm{u}-\mathrm{AQP} 2$ reached a plateau in CKD patients. By the end of the examination day, there was no difference between the groups.

GFR decreased in controls during the infusion period and reached baseline levels one hour after infusion had ceased. In CKD patients, however, GFR was unchanged during the infusion period after which GFR increased towards the end of the study day.

Mean baseline levels of UO were lower in the patient group than in controls. In both groups, the hypertonic saline induced a significant reduction. Initially, UO decreased less in CKD patients than in controls (mean difference at 150 min patients: $-15 \% \pm 31$ vs. controls: $-56 \% \pm 17$ ), $p=0.03\}$. At the end of the examination, the relative decrease in UO in CKD patients was significantly lower than controls $\{$ (mean difference at 240 min patients: $-29 \% \pm 39$ vs. controls: $-64 \% \pm 25), p=0.02\}$.

At baseline u-osm were higher in patients than controls, but there was no significant difference. U-osm increased significantly in both groups during 3\% hypertonic saline, but to a higher extent in controls than in patients $\{$ (mean difference at 240 min patients: $289 \pm 155 \%$ vs. mean difference controls: $125 \pm 141 \%), p=0.001\}$.

At baseline, $\mathrm{C}_{\mathrm{H} 2 \mathrm{O}}$ was lower in the CKD patient group compared to controls and decreased significantly in both groups, but less in CKD patients. Both groups changed from positive values at baseline to negative values after infusion indicating a change from free water excretion to water reabsorption. $\mathrm{C}_{\mathrm{H} 2 \mathrm{O}}$ remained higher in CKD patients compared to controls throughout the examination day, but the relative change did not differ significantly \{(mean difference at 240 min: patients: $-132 \% \pm 122$ vs. controls: $-155 \% \pm 55), p=0.099$ \} .

\section{Excretion of sodium, potassium, u-NKCC2 and $\mathrm{u}-\mathrm{ENaCY}$}

Figure $3 \mathrm{~B}$ and $3 \mathrm{C}$ shows the change in $\mathrm{u}-\mathrm{ENaC \gamma}$ and $\mathrm{u}-\mathrm{NKCC}$. Figure 4E-F shows the change in $\mathrm{FE}_{\mathrm{Na}}$, and $\mathrm{FE}_{\mathrm{K}}$ during the study day. At baseline $\mathrm{FE}_{\mathrm{Na}}$ and $\mathrm{FE}_{\mathrm{K}}$ were higher in CKD patients compared to controls. After hypertonic saline, $\mathrm{FE}_{\mathrm{Na}}$ increased significantly and $\mathrm{FE}_{\mathrm{K}}$ decreased significantly in both groups.

There was no difference in $\mathrm{u}-\mathrm{NKCC} 2$ at baseline between CKD patients and controls. However, u-NKCC2 increased significantly in the CKD patient group and decreased significantly in the control group, in response to 
Table 1 Baseline characteristics and 24-hour urine collection in 23 patients with CKD and 24 healthy controls

\begin{tabular}{|c|c|c|c|}
\hline & $\begin{array}{l}\text { Patients } \\
(n=23)\end{array}$ & $\begin{array}{c}\text { Healthy Controls } \\
(\mathrm{n}=24)\end{array}$ & $p$ value \\
\hline Gender, n (Female/Male) (\%) & $6(26) / 17(74)$ & $6(25) / 18(75)$ & \\
\hline \multicolumn{4}{|l|}{ Age (years) } \\
\hline Males & $60 \pm 10$ & $58 \pm 9$ & 0.52 \\
\hline Females & $63 \pm 8$ & $60 \pm 8$ & 0.53 \\
\hline \multicolumn{4}{|l|}{ Body Mass Index $\left(\mathrm{kg} / \mathrm{m}^{2}\right)$} \\
\hline Males & $27.4 \pm 2.6$ & $25.6 \pm 2.2$ & 0.03 \\
\hline Females & $24.4 \pm 4.4$ & $23.2 \pm 1.6$ & 0.54 \\
\hline 24-h BP (mmHg) & $124 / 76 \pm 15 / 8$ & $123 / 74 \pm 7 / 5$ & $0.72 / 0.25$ \\
\hline Pulse Rate $\left(\mathrm{min}^{-1}\right)$ & $68 \pm 10$ & $65 \pm 8$ & 0.19 \\
\hline \multicolumn{4}{|l|}{ Screening Biochemistry } \\
\hline p-sodium (mmol/l) & $141 \pm 2$ & $142 \pm 2$ & 0.22 \\
\hline p-potassium (mmol/l) & $4.4 \pm 0.6$ & $4.0 \pm 0.3$ & 0.02 \\
\hline $\mathrm{p}$-albumin $(\mathrm{g} / \mathrm{l})$ & $43 \pm 3$ & $43 \pm 2$ & 0.34 \\
\hline p-hemoglobin (mmol/l) & $8.4 \pm 0.7$ & $8.9 \pm 0.7$ & 0.01 \\
\hline p-creatinine $(\mu \mathrm{mol} / \mathrm{l}))$ & $199.7 \pm 81.6$ & $76.7 \pm 12.0$ & $<0.0001$ \\
\hline eGFR (ml/min) & $31 \pm 15$ & $87 \pm 15$ & $<0.0001$ \\
\hline p-urea $(\mathrm{mmol} / \mathrm{l})$ & $12.7 \pm 4.9$ & $5.1 \pm 1.2$ & $<0.0001$ \\
\hline u-albumin (mg/l) & $8(5 ; 65)$ & $5(2 ; 8)$ & 0.01 \\
\hline \multicolumn{4}{|l|}{ 24-h urine collection } \\
\hline Urine Output (ml/24 h) & $2741 \pm 753$ & $2667 \pm 817$ & 0.75 \\
\hline u-osm (mosm/24 h) & $831 \pm 219$ & $917 \pm 150$ & 0.12 \\
\hline $\mathrm{C}_{\mathrm{H} 2 \mathrm{O}}(\mathrm{ml} / \mathrm{min})$ & $-0.029 \pm 0.52$ & $-0.355 \pm 0.56$ & 0.04 \\
\hline Creatinin Clearance $\mathrm{ml} / \mathrm{min}^{*} \mathrm{~m}^{2}$ & $46 \pm 21$ & $114 \pm 17$ & $<0.0001$ \\
\hline u-AQP2 (ng/mmol) & $144 \pm 29$ & $139 \pm 23$ & 0.55 \\
\hline $\mathrm{u}-\mathrm{ENaC}$ (ng/mmol) & $96 \pm 41$ & $90 \pm 33$ & 0.55 \\
\hline u-NKCC2 (ng/mmol) & $377 \pm 99$ & $365 \pm 98$ & 0.70 \\
\hline $\mathrm{u}-\mathrm{Na}(\mu \mathrm{mol} / \mathrm{min})$ & $99 \pm 37$ & $94 \pm 32$ & 0.63 \\
\hline $\mathrm{FE}_{\mathrm{Na}}(\%)$ & $1.71 \pm 0.99$ & $0.53 \pm 0.19$ & $<0.0001$ \\
\hline $\mathrm{u}-\mathrm{K}(\mu \mathrm{mol} / \mathrm{min})$ & $47(37 ; 53)$ & $50(46 ; 59)$ & 0.11 \\
\hline $\mathrm{FE}_{\mathrm{K}}(\%)$ & $21(16 ; 28)$ & $11(9 ; 12)$ & $<0.0001$ \\
\hline
\end{tabular}

Values are means $\pm \mathrm{SD}$. U-albumin is the median with $25^{\text {th }}$ and $75^{\text {th }}$ percentiles in brackets.

$\mathrm{BP}$, Blood pressure; eGFR, estimated glomerular filtration rate. Urine osmolality (u-osm), free water clearance $\left(\mathrm{C}_{\mathrm{H} 2 \mathrm{O}}\right), \mathrm{urinary}$ excretion of $\mathrm{AQP} 2$ ( $\left.\mathrm{u}-\mathrm{AQP} 2\right)$, ENaC $\mathrm{C}$ $\left(\mathrm{u}-\mathrm{ENaC}\right.$ ) and NKCC2 (u-NKCC2) corrected for creatinin, urinary sodium excretion rate $(\mathrm{u}-\mathrm{Na})$, fractional excretion of sodium ( $\left.\mathrm{FE} \mathrm{Na}_{\mathrm{Na}}\right)$, urinary potassium excretion rate $(\mathrm{U}-\mathrm{K})$ and fractional excretion of potassium $\left(\mathrm{FE}_{\mathrm{K}}\right)$.

$P$ values in right column represent the probability of a difference between groups.

hypertonic saline infusion. At the end of examination, there was no difference between the two groups. However, the relative change in $\mathrm{u}-\mathrm{NKCC} 2$ was significant higher in CKD patients than controls \{(mean difference at 240 min patients: $10 \% \pm 28$ vs. controls: $-10 \% \pm 27$ ), $p=0.028\}$.

At baseline, $\mathrm{u}-\mathrm{ENaC} \gamma$ was higher in $\mathrm{CKD}$ patients, but the difference was not significant. During the examination day, there was a general trend towards a reduction in $\mathrm{u}-\mathrm{ENaC} \gamma$ in CKD patients and an increase in controls, but it was not statistically significant. Nor were there a difference in the relative changes in $\mathrm{u}-\mathrm{ENaC} \gamma$ between CKD patients and controls throughout the examination day.

\section{High $u-A Q P 2$ and $u-N K C C 2$ in patients with kidney failure} stage IV

We performed a post hoc sub analysis of $\mathrm{u}-\mathrm{NKCC} 2$, $\mathrm{uAQP} 2$ and $\mathrm{u}-\mathrm{ENaC \gamma}$ dividing patients with CKD into GFR $\leq 30 \mathrm{ml} / \mathrm{min} / 1.73 \mathrm{~m}^{2}$ i.e. stage IV $(\mathrm{n}=11$; mean GFR: $21 \mathrm{ml} / \mathrm{min} / 1.73 \mathrm{~m}^{2}$ ) and GFR $>30 \mathrm{ml} / \mathrm{min} /$ 


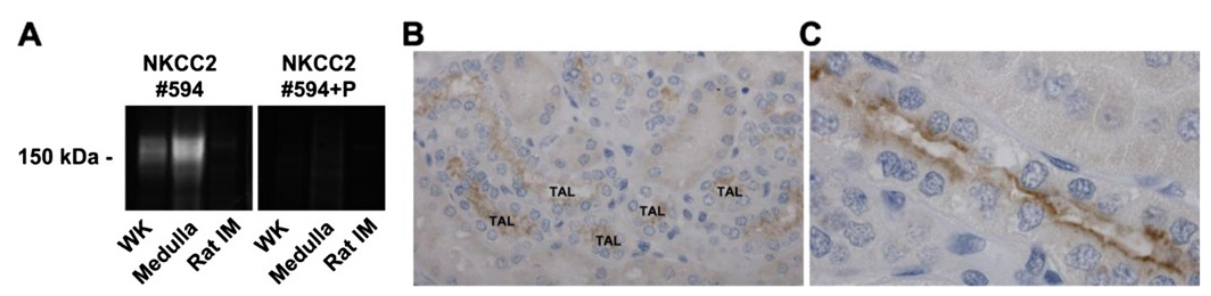

Figure 2 NKCC2 antibody characterization. A) Western blotting using a novel human NKCC2 specific antibody. The affinity-purified antibody (\#594), detected a glycosylated smear characteristic of NKCC2 in human whole kidney (WK) and medulla samples, but not in rat inner medulla (IM). This signal was not observed following pre-incubation of the antibody with the immunizing peptide (P). B) Immunohistochemistry of a human kidney section using the novel NKCC2 antibody. Labeling was confined to the TAL. C) At higher magnification, the majority of NKCC2 signal was detected at the apical pole of TAL cells.

$1.73 \mathrm{~m}^{2}$ i.e. stage III ( $\mathrm{n}=9$; mean GFR: $48 \mathrm{ml} / \mathrm{min} /$ $1.73 \mathrm{~m}^{2}$ ) (Figure 3D-F).

Patients with CKD stage IV had a higher u-AQP2, at baseline, than CKD stage III and $\mathrm{u}-\mathrm{AQP} 2$ remained significantly higher throughout the examination day (Figure 3D). There were no detectable differences in $\mathrm{u}$ $\mathrm{ENaC} \gamma$ either at baseline or after hypertonic saline infusion (Figure 3E). U-NKCC2 was significantly higher in patients with CKD stage IV than CKD stage III, both at baseline and in response to hypertonic saline infusion (Figure 3F).

\section{Vasoactive hormones}

Figure 5 shows PRC, p-Ang II, p-Aldo and p-AVP. At baseline, there were significantly higher levels of PRC and p-Aldo in CKD patients, but p-Ang II did not differ between groups. All three hormones were suppressed in response to hypertonic saline in both groups. PRC and p-Aldo levels remained significantly higher in CKD patients than controls after hypertonic saline infusion. One patient received spironolactone and elevated aldosterone. Exclusion of this subject from analysis had no impact on the overall results.

P-AVP was higher at baseline in CKD patients compared to controls. P-AVP increased significantly in both groups and to the same extent in response to hypertonic saline infusion, with a maximum at $150 \mathrm{~min}$ and a uniform steady reduction during the post infusion period. Dividing patients according to stage of CKD showed that p-AVP tended to be higher in CKD stage IV than CKD stage III, but there was no significant difference (data not shown).

\section{Plasma sodium, -potassium and -osmolality}

At baseline, CKD patients had a significantly lower $\mathrm{p}-\mathrm{Na}$ ( $\mathrm{p}<0.05)$. P-Na increased in response to hypertonic saline in both groups. The increase in $\mathrm{p}-\mathrm{Na}$ was higher in patients compared to healthy controls at the end of the examination day, but it was not significant (patients: $2 \pm$ $0.8 \%$ vs. controls: $1.6 \pm 0.8 \% ; \mathrm{p}=0.082)$. Patients with CKD had higher $\mathrm{p}$-osm than controls $(\mathrm{p}<0.0001)$. P-Osm increased to the same extent in both groups in response to hypertonic saline infusion. P-K was significant higher in the patient group throughout the examination day $(p=0.001)$, but did not change in response to hypertonic saline $(\mathrm{p}=0.147)$ (data not shown).

\section{Bioimpedance spectroscopy}

Figure 6 shows the changes in TBW, ICV and ECV during the baseline period, infusion period and post infusion period.

The two groups received the same volume of hypertonic saline (patients: $557 \pm 87 \mathrm{ml}$ vs. controls: $533 \pm 79 \mathrm{ml}$; $\mathrm{p}=0.331$ ) and an additional $1925 \mathrm{ml}$ of tap water. As expected, when administering hypertonic saline, ICV decreased while ECV increased during the infusion period reaching a new steady state in the post infusion period. TBW also increased slightly and reached a maximum at the end of study day. Although there was a tendency towards a lower ICV and a higher ECV in CKD patients there were no statistically significant differences in the volume status between the patient and the control group. CKD patients also had a higher adipose tissue mass (ATM) compared to healthy controls $\{27.4 \pm 9.4 \mathrm{~kg}$ vs. $32.1 \pm 9.4 \mathrm{~kg} ; \mathrm{p}<0.002\}$, but lean tissue mass (LTM) did not differ between the two groups $\{47.4 \pm 9.7 \mathrm{~kg}$ vs. $47.9 \pm 10.3 \mathrm{~kg} ; \mathrm{p}=0.470\}$.

\section{Discussion}

In the present study, we measured u-NKCC2, u-AQP2, and $\mathrm{u}-\mathrm{ENaC} \gamma$ in CKD patients stage III-IV and healthy controls at baseline and in response to an intravenous volume load of $3.0 \%$ hypertonic saline in order to estimate and analyze sodium- and water channel function in patients with CKD compared to healthy controls. The novelty of this study is two-fold: 1) This is the first study that documents the changes in $\mathrm{u}$-NKCC2 in healthy subjects as well in patients with CKD in response to a hypertonic saline load, 2) Measurements of the urinary excretion of NKCC2, AQP2 and $\mathrm{ENaC \gamma}$ in the same study has never been performed previously. 


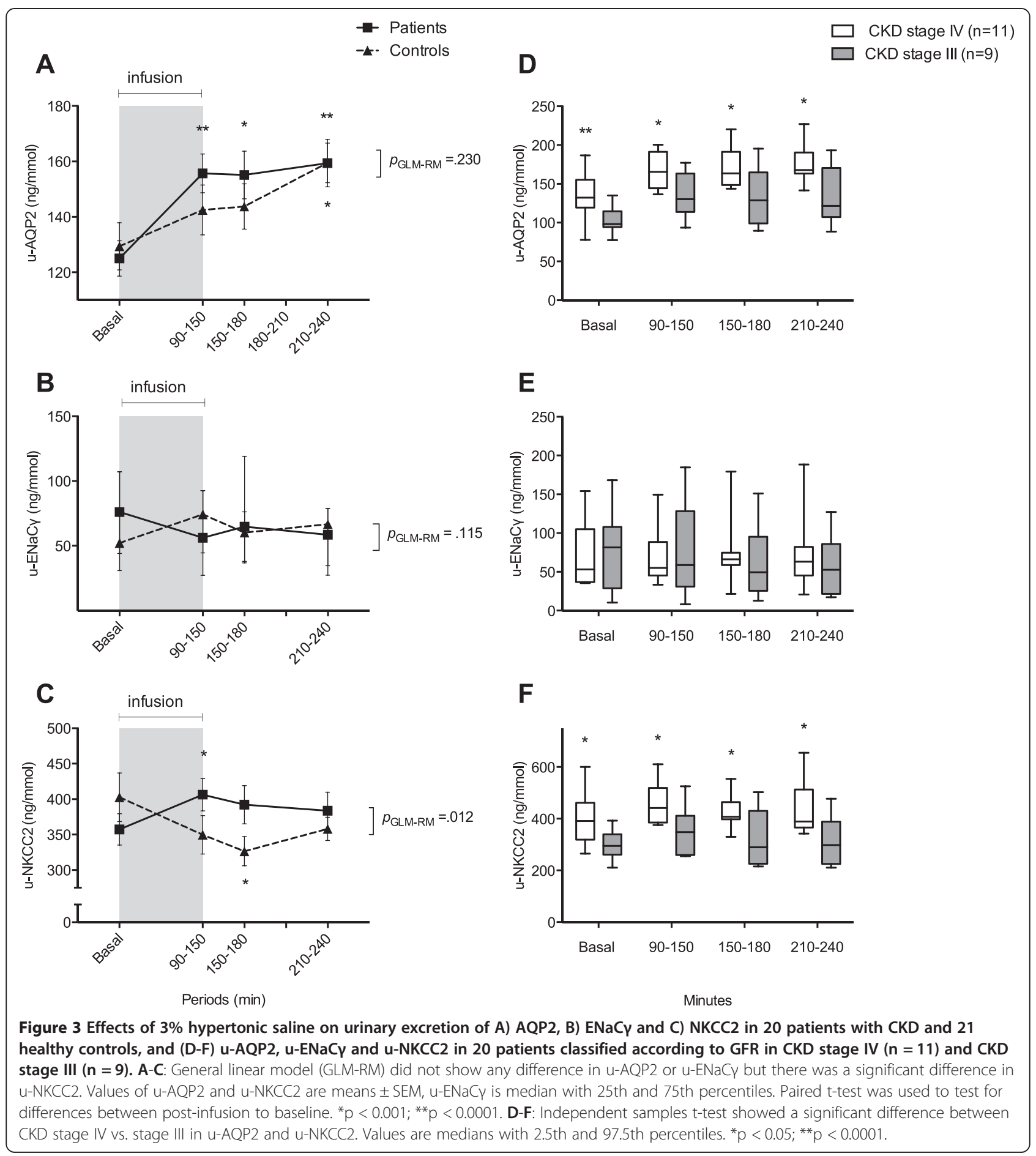

When compared to the patient group as a whole, there were no measurable differences in $\mathrm{u}-\mathrm{NKCC} 2, \mathrm{u}-\mathrm{AQP} 2$ and $\mathrm{u}-\mathrm{ENaC} \gamma$ at baseline. In response to hypertonic saline, u-NKCC2 increased, u-AQP2 increased excessively and $\mathrm{u}-\mathrm{ENaC}$ decreased in $\mathrm{CKD}$ patients compared to healthy controls. When patient groups were compared according to stage of CKD, there was a significant increase in $\mathrm{u}-\mathrm{NKCC} 2$ and $\mathrm{u}-\mathrm{AQP} 2$ in patients with $\mathrm{CKD}$ stage IV compared to CKD stage III, both at baseline and in response to hypertonic saline. This study further confirmed that patients with CKD stage III-IV showed a reduced renal concentrating ability compared to healthy subjects.

In this study, we used a novel and original method to evaluate sodium reabsorption in the ascending limb of Henles loop using a radioimmunoassay of urinary NKCC2. 


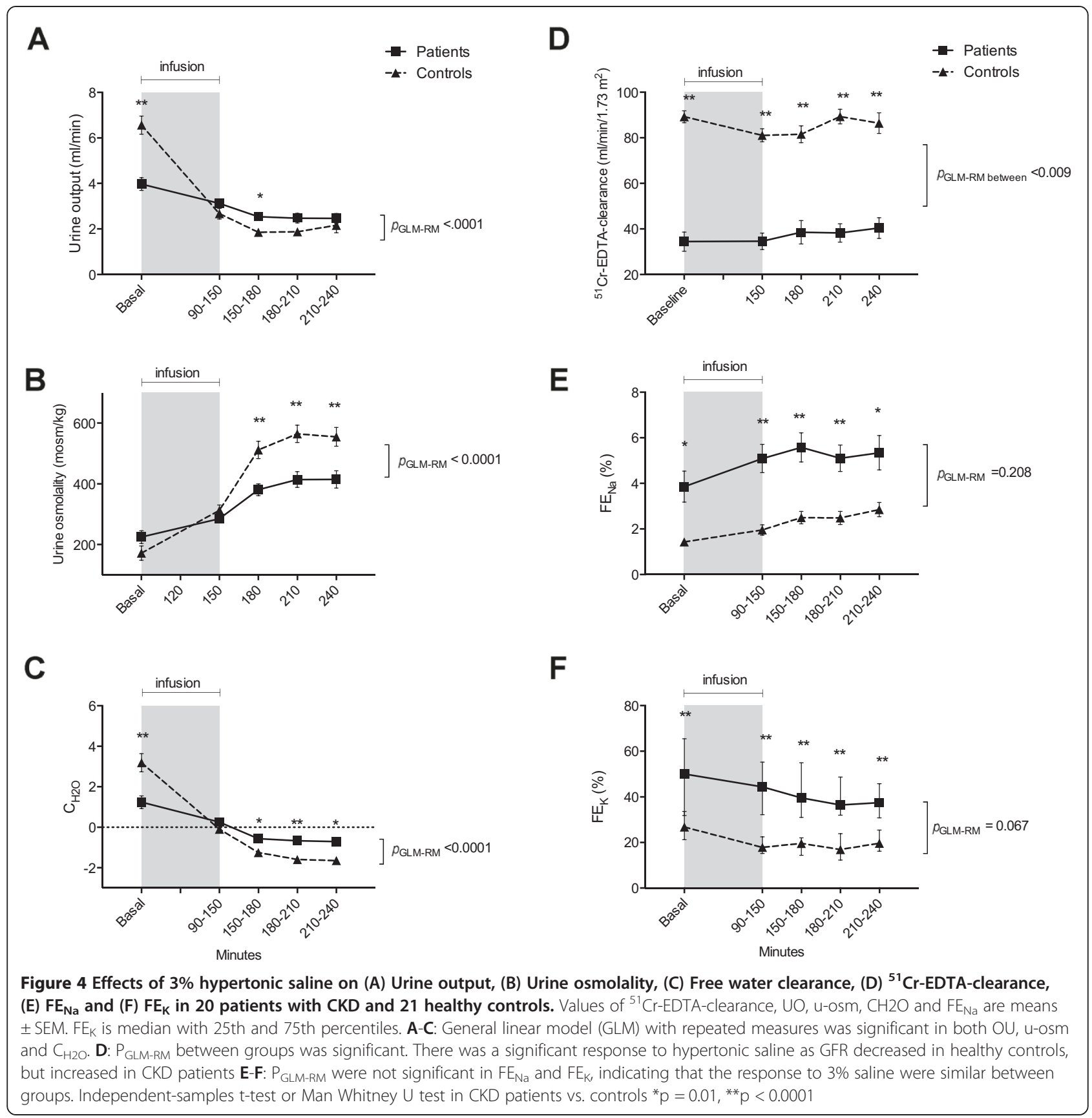

The quantity of excreted NKCC2 in urine is supposed to reflect the activity of sodium transport via NKCC2, just as $\mathrm{u}$-AQP2 reflects the functional status of AQP2 water channels $[9,18,22-24]$ and $\mathrm{u}-\mathrm{ENaC \gamma}$ reflects the functional status of $\mathrm{ENaC}$ in the principal cells $[20,25]$. The signal that is being quantified is derived from specific antibody binding against peptides of NKCC2 as in $\mathrm{AQP} 2$ and $\mathrm{ENaC} \gamma$ - likely in urinary exosomes. Traditionally, tubular transporters are excreted in urinary exosomes, containing apical membrane and intracellular fluid [26,27]. Isobe et al. found an increased total and phosphorylated NCC in urinary exosomes in patients with PHAII and Lubbe et al. also found an increased number of phosphorylated NCC in urinary exosomes in patients with primary hyperaldosteronism $[28,29]$. Thus, there is evidence that the differences in transporters are due to higher protein abundance in the exosomes. It is well established that there is an increased trafficking of vesicles to the apical membrane upon stimulation [27,30,31]. However, it is unclear to what extent, there is an increased rate of shedding of the plasma membrane into exosomes. 


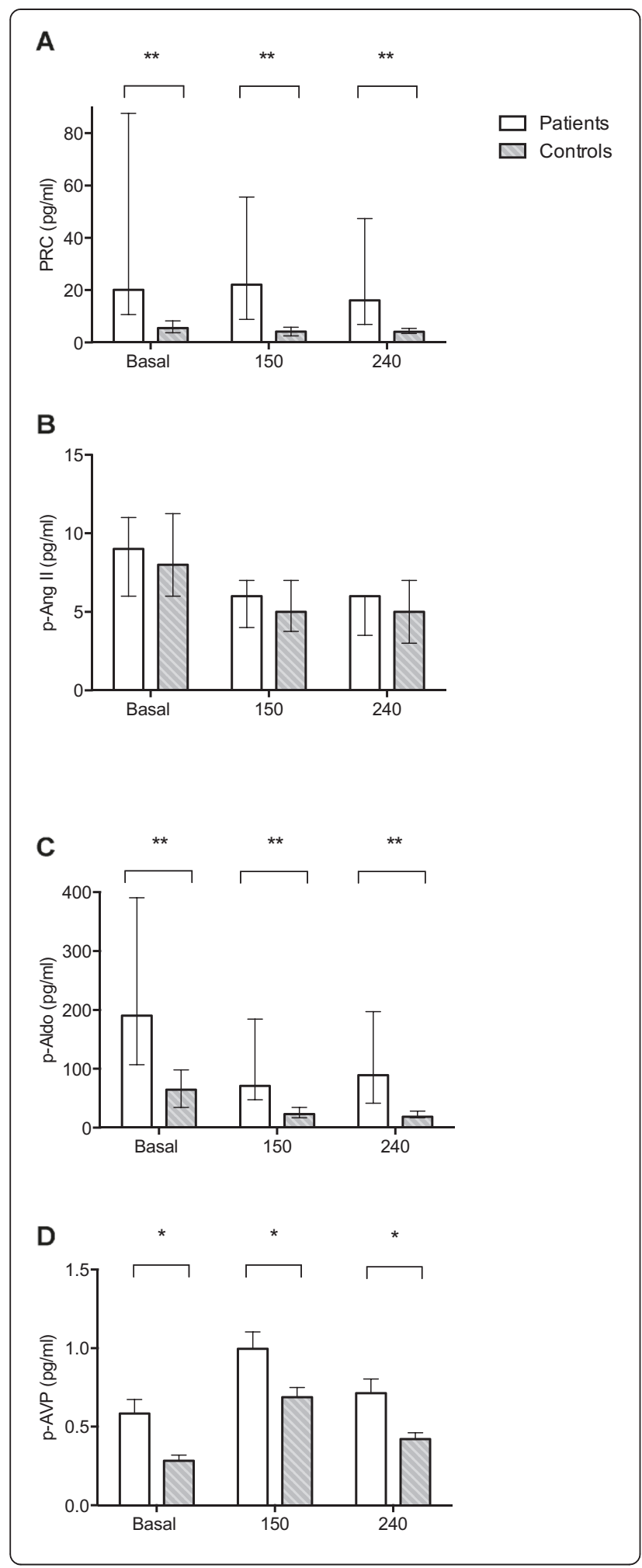

Figure 5 Effects of 3\% hypertonic saline on plasma concentrations of Renin (A), angiotensin II (B), aldosterone (C) and vasopressin (D). PRC, p-ang $\|$ and $p$-aldo are presented as medians \pm 25 th and 75 th percentiles. P-AVP is mean \pm SEM. A-C: Both groups decreased in response to hypertonic saline. PRC and p-Aldo were significant higher in the patient group. D: There was a significant difference in $\mathrm{p}$-AVP between groups, but the response to hypertonic saline did not differ ( $p G L M-R M=0.970)$.

Independent-samples t-test or Man Whitney $U$ test in CKD patients vs. controls ${ }^{*} p=0.01,{ }^{* *} p<0.0001$.

Reabsorption of sodium via NKCC2 in the TAL is critical for the establishment of a hypertonic medullary interstitium and urine concentration $[3,32,33]$. In animals, AVP has been demonstrated to increase NKCC2 activity [34]. This effect is mediated by V2 receptors via Adenylate Cyclase 6, which facilitate phosphorylation and trafficking of NKCC2 to the apical membrane, thereby increasing $\mathrm{NaCl}$ reabsorption [31,34-36]. In humans, the regulation of NKCC2 is still unknown both under physiological as well as pathophysiological conditions. However, enhanced $\mathrm{NaCl}$ reabsorption via NKCC2 is associated with hypertension and decreased $\mathrm{NaCl}$ transport via $\mathrm{NKCC} 2$ results in low blood pressure, as seen in Bartter's syndrome $[12,37]$.

In response to hypertonic saline, a decrease in $\mathrm{u}-\mathrm{NKCC} 2$ was observed in healthy controls, which is inconsistent with animal studies showing that AVP increases NKCC2 expression via a short-term mechanism $[31,34]$. However, as NKCC2 is associated to exosomes, which results from retrieval of plasma membrane proteins following agonist removal, there has to be a point where membrane NKCC2 increases before $\mathrm{u}-\mathrm{NKCC} 2$ increases. Thus, due to a delayed response, a lack of change in u-NKCC2 does not necessarily reflect a lack of change within the plasma membrane of kidney epithelial cells. Therefor, AVP probably did play a role, but we did not see the full impact.

In patients with CKD, u-NKCC2 increased in response to hypertonic saline. When patients were grouped according to CKD stage IV and III, it was evident that patients with stage IV CKD had an abnormal increased excretion of NKCC2 at baseline and in response to hypertonic saline. There might be several explanations: Firstly, it seems feasible that fractional decreased proximal tubular sodium absorption might contribute to an exaggerated increase in sodium absorption via NKCC2 in CKD compared to healthy controls. Secondly, high p-AVP was apparent in $\mathrm{CKD}$, and it has been reported that long-term elevated AVP up regulates the expression of NKCC2 to obtain maximal urinary concentration [34]. Thirdly, the increased $\mathrm{u}-\mathrm{NKCC} 2$ in patients with CKD may be a compensatory phenomenon that reflects the need of more active sodium transport in the remaining thick ascending limbs to create 


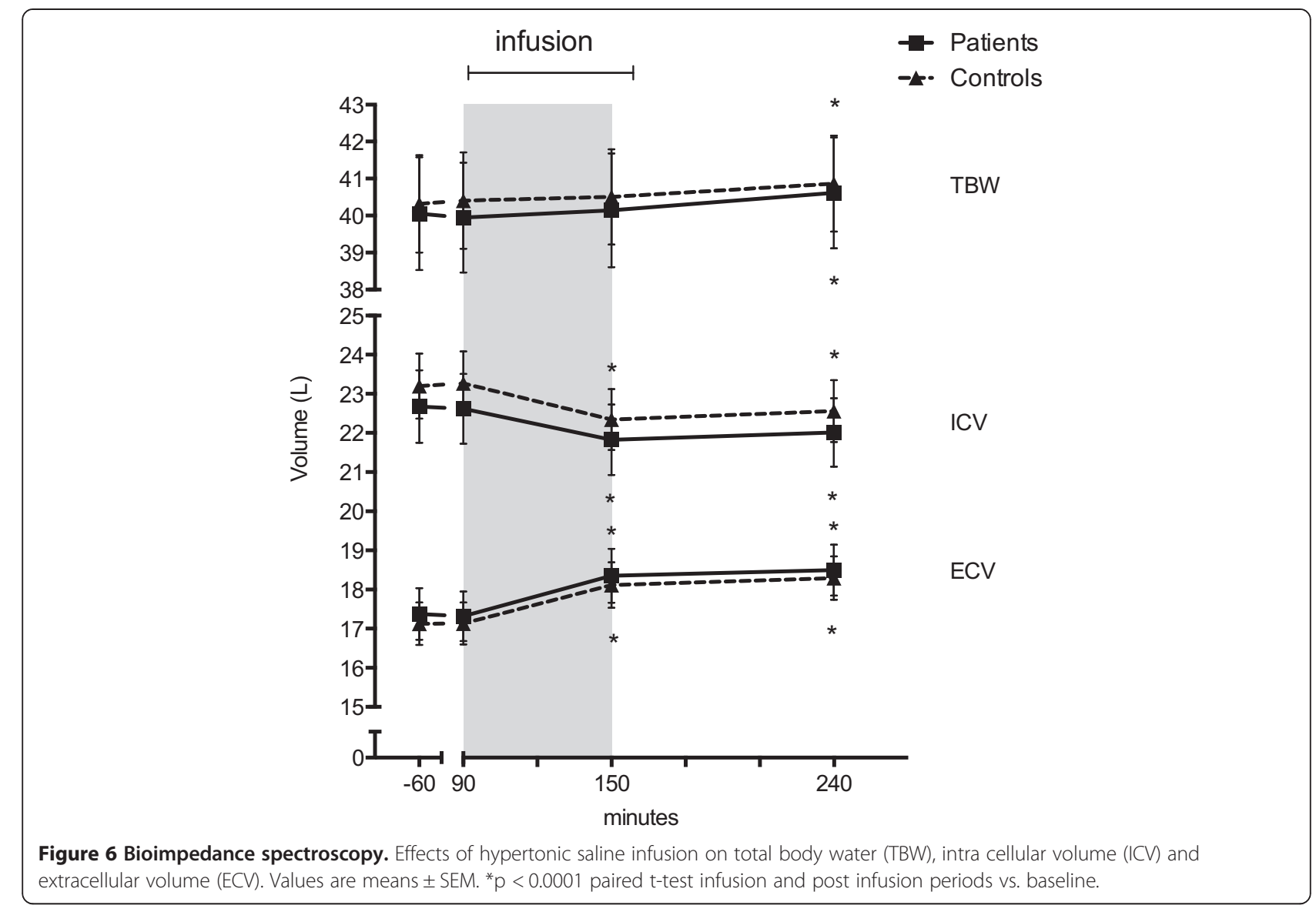

a sufficient level of medullary hypertonicity to enhance water reabsorption via AQP2 along the collecting ducts.

U-AQP2 increased in both groups after hypertonic saline. Recently, and in agreement with the present study, our group reported an increase in u-AQP2 in response to hypertonic saline in healthy young subjects [38]. U-AQP2 increased excessively in CKD patients during the infusion period, and it was clearly illustrated in the post-hoc sub-analysis that patients with stage IV CKD had a significant higher u-AQP2, and thus an evidently abnormal response. Two previous studies have compared $\mathrm{u}-\mathrm{AQP} 2$ in patients with CKD and diabetic nephropathy to healthy controls $[9,39]$. Both studies, however, found a reduced $\mathrm{u}-\mathrm{AQP} 2$ in patients compared to controls. Firstly, in this study, the concentrating mechanism was manipulated by use of an acute volume expansion with hypertonic saline. In the previous studies, the urine concentrating mechanism was performed by $8-12$ hours of water deprivation. The mechanisms involved might be different and explain the discrepancy in u-AQP2. Secondly, it has been demonstrated that fractional water reabsorption is reduced in the proximal nephron parts in CRF rats treated with volume expansion [40]. It is possible that a decrease in water reabsorption in proximal tubules is followed by a larger compensatory reabsorption of water in the collecting ducts of patients with CKD compared to healthy controls and patients with moderate renal impairment. Thirdly, as mentioned earlier, the increased u-NKCC2 in patients with CKD, may enhance medullary hypertonicity to increase water reabsorption via AQP2.

In response to hypertonic saline, $\mathrm{UO}$ and $\mathrm{C}_{\mathrm{H} 2 \mathrm{O}}$ decreased less pronounced in patients with CKD compared to controls. Thus, patients reabsorbed less water despite that patients exhibited higher $\mathrm{u}-\mathrm{AQP} 2$ and $\mathrm{p}-\mathrm{AVP}$. Increased p-AVP, in CKD, might be compensatory to stimulate the remaining AQP2 water channels adequately, in order to concentrate urine. Indeed, increased p-AVP has been reported in rats with CRF and patients maintained on hemodialysis [41,42]. Although AVP increased the number of activated AQP2 water channels, it might not have been sufficient, to reabsorb the proper amount of water via AQP2. Thus, despite increased $\mathrm{u}-\mathrm{AQP} 2, \mathrm{C}_{\mathrm{H} 2 \mathrm{O}}$ was less pronounced in patients compared to healthy controls, and thus concentration ability was compromised. Studies have indicated that defective urinary concentration ability may be an impairment of the AVP stimulated water reabsorption in the collecting ducts, either by an AVP resistant down regulation of AQP2 or down regulation of the V2 receptor protein [43-45]. To support this fact, 
there was no difference in baseline $\mathrm{u}-\mathrm{AQP} 2$, but twice as high $\mathrm{p}$-AVP in CKD patients compared to controls.

Thus, u-AQP2 was abnormal in CKD patients, and apparently more pronounced in patients with severe renal impairment. Perhaps due to an impaired response to AVP stimulation or a compensatory response to increased sodium reabsorption via NKCC2.

In the distal tubules, sodium transport occurs via the $\mathrm{ENaC}$ in the luminal membrane of principal cells [46]. P-aldo was increased by a factor three in CKD patients compared to controls. It is well known in CKD [47-49]. As aldosterone regulates $\mathrm{ENaC}$, we initially expected a major difference in $\mathrm{u}-\mathrm{ENaC} \gamma$. However, aldosterone increases $\mathrm{ENaC} \gamma$-cleavage and not its expression [50]. This might explain in part, why $\mathrm{u}-\mathrm{ENaC} \gamma$ was not increased despite high p-aldo in CKD patients. However, due to the time lag of aldosterone's action on sodium balance, it is unlikely that aldosterone had any major impact on the changes in $\mathrm{u}-\mathrm{ENaC} \gamma$ during the study day. In CKD patients, we measured a decreased $\mathrm{u}-\mathrm{ENaC} \gamma$ in response to hypertonic saline, indicating a decreased sodium reabsorption via ENaC. Apparently, and opposite healthy controls, CKD patients might decrease their sodium reabsorption via $\mathrm{ENaC}$ to compensate for an increased reabsorption via the NKCC2 channels. Thus, the decrease in $\mathrm{u}-\mathrm{ENaC} \gamma$ in $\mathrm{CKD}$ patients and the increase in $\mathrm{u}-\mathrm{ENaC} \gamma$ in healthy controls might be compensatory mechanisms due to an altered absorptive activity in NKCC2, but further studies are necessary to clarify this hypothesis..

\section{Estimation of body fluid volumes by bioimpedance spectroscopy}

The determination of body fluid volumes via bioimpedance spectroscopy (BIS) is an accurate method for estimating total body water and the distribution of water between the intracellular and extracellular spaces [51]. In this present study, we measured no statistical difference between the two groups, but ICV was lower and ECV and TBW were increased in patients with CKD compared to controls. This is in agreement with previous findings [52,53]. We expected a more pronounced increase in TBW in patients with CKD, but the differences in ECV and ICV between CKD patients and controls were very small. There might have been a difference in body fluid volumes between CKD patients and healthy controls, but it was not detected in the present study, possibly due to the small number of subjects in each group.

\section{Strengths and limitations}

The major strength of this study was the design as a casecontrolled interventional study with an age and gender matched group of healthy controls. The test conditions were very well defined regarding diet, sodium and fluid intake. Thus, the results are not confounded by differences in intake of sodium and water. In addition, the study population was well defined, regarding renal function, and had moderately to severe reduced renal function. Although we found a significant difference in $\mathrm{u}-\mathrm{NKCC} 2$ and $\mathrm{u}-\mathrm{AQP} 2$ in stage IV CKD patients compared to CKD stage III, we must emphasize that it was a post-hoc analysis. This study was not conducted to demonstrate changes between CKD stages. Therefore the results are indicative and further studies must be performed to elucidate these findings.

Also, the causes of CKD were a mixture of primary diseases that may have hidden important information. We tested the handling of sodium and water in CKD in patients, who were receiving antihypertensive treatment, including diuretics, during the study period. Although the study was performed under standardized conditions, this could be a source of error as it may influence the excretion of sodium and components of RAAS. However, we tried to compensate for this by securing the subjects were in a fasting condition, and their morning prescription was postponed to the end of the examination day. We did not find it ethically justified to withdraw medication for a longer period. To overcome this, we could have compared CKD patients to a second control group of hypertensive patients with normal renal function but receiving similar therapy.

\section{Conclusions}

After hypertonic saline, $\mathrm{u}-\mathrm{NKCC} 2$ increased, in patients with CKD compared to healthy controls, thus indicating an increased sodium reabsorption via the NKCC2 transporter in CKD. U-AQP2 increased more in CKD patients, despite an attenuated decrease in $\mathrm{C}_{\mathrm{H} 2 \mathrm{O}}$ in $\mathrm{CKD}$ compared to healthy controls. Thus, the ability to concentrate urine was clearly impaired in patients with CKD.

In conclusion, though high levels of aldosteron and vasopressin, patients with CKD can only partly compensate and counteract an acute volume expansion with 3\% hypertonic saline, due to a defective tubular function.

\section{Competing interests}

The authors declare that they have no competing interests. The authors alone are responsible for the content and writing of this paper.

\section{Authors' contributions}

All authors have contributed to the manuscript. JMJ, FHM and EBP designed the project. JMJ, FHM and AEO performed the experiments and statistical analyzes. RAF performed the NKCC2 antibody characterization. JMJ, FHM, JNB, RAF and EBP wrote and edited the manuscript. All authors read and approved the final manuscript.

\section{Acknowledgements}

The authors greatly acknowledge the skillful assistance of our laboratory technicians: Anne Mette Ravn, Kirsten Nygaard, Henriette Vorup Simonsen, Susan Milton Rasmussen, Helle Høyer and Inger-Merete Paulsen. 


\section{Funding}

The study was supported by grants from The Lundbeck Foundation, Aase and Ejnar Danielsens Foundation, Helen and Ejnar Bjoernows Foundation, Region Midjutlands Research Fund and the Danish Medical Research Foundation.

\section{Author details}

'Department of Medical Research, Holstebro Hospital, University Clinic in Nephrology and Hypertension, Laegaardvej 12, 7500 Holstebro, Denmark. ${ }^{2}$ Regional Hospital Jutland West and Aarhus University, Aarhus, Denmark. ${ }^{3}$ Department of Biomedicine, Aarhus University, Aarhus, Denmark.

Received: 27 February 2014 Accepted: 11 June 2014

Published: 26 June 2014

\section{References}

1. Hayslett JP, Kashgarian M, Epstein FH: Mechanism of change in the excretion of sodium per nephron when renal mass is reduced. J Clin Invest 1969, 48(6):1002-1006.

2. Kwon TH, Frokiaer J, Fernandez-Llama P, Maunsbach AB, Knepper MA, Nielsen S: Altered expression of Na transporters NHE-3, NaPi-II, Na-K-ATPase, BSC-1, and TSC in CRF rat kidneys. Am J Physiol 1999, 277(2 Pt 2):F257-F270.

3. Tannen RL, Regal EM, Dunn MJ, Schrier RW: Vasopressin-resistant hyposthenuria in advanced chronic renal disease. N Engl J Med 1969, 280(21):1135-1141.

4. Michimata M, Kazama I, Mizukami K, Araki T, Nakamura Y, Suzuki M, Wang W, Fujimori K, Satomi S, Ito S, Imai Y, Matsubara M: Urinary concentration defect and limited expression of sodium cotransporter, $\mathrm{rBSC} 1$, in a rat model of chronic renal failure. Nephron Physiol 2003, 93(2):34-41.

5. DiGiovanni SR, Nielsen S, Christensen El, Knepper MA: Regulation of collecting duct water channel expression by vasopressin in Brattleboro rat. Proc Natl Acad Sci U S A 1994, 91(19):8984-8988.

6. Kanno K, Sasaki S, Hirata Y, Ishikawa S, Fushimi K, Nakanishi S, Bichet DG, Marumo F: Urinary excretion of aquaporin-2 in patients with diabetes insipidus. N Engl J Med 1995, 332(23):1540-1545.

7. Deen PM, van Aubel RA, van Lieburg AF, van Os CH: Urinary content of aquaporin 1 and 2 in nephrogenic diabetes insipidus. J Am Soc Nephrol 1996, 7(6):836-841

8. Nielsen S, Kwon TH, Frokiaer J, Agre P: Regulation and dysregulation of aquaporins in water balance disorders. J Intern Med 2007, 261(1):53-64.

9. Pedersen EB, Thomsen IM, Lauridsen TG: Abnormal function of the vasopressin-cyclic-AMP-aquaporin2 axis during urine concentrating and diluting in patients with reduced renal function. A case control study. BMC Nephrol 2010, 11:26.

10. Oh YS, Warnock DG: Disorders of the epithelial $\mathrm{Na}(+)$ channel in Liddle's syndrome and autosomal recessive pseudohypoaldosteronism type 1 . Exp Nephrol 2000, 8(6):320-325.

11. Ecelbarger CA, Tiwari S: Sodium transporters in the distal nephron and disease implications. Curr Hypertens Rep 2006, 8(2):158-165.

12. Ares GR, Caceres PS, Ortiz PA: Molecular regulation of NKCC2 in the thick ascending limb. Am J Physiol Renal Physiol 2011, 301(6):F1143-F1159.

13. McKee JA, Kumar S, Ecelbarger CA, Fernandez-Llama P, Terris J, Knepper MA Detection of $\mathrm{Na}(+)$ transporter proteins in urine. J Am Soc Nephrol 2000, 11(11):2128-2132.

14. du Cheyron D, Daubin C, Poggioli J, Ramakers M, Houillier P, Charbonneau $P$, Paillard M: Urinary measurement of $\mathrm{Na}+\mathrm{H}+$ exchanger isoform 3 (NHE3) protein as new marker of tubule injury in critically ill patients with ARF. Am J Kidney Dis 2003, 42(3):497-506.

15. Riazi S, Madala-Halagappa VK, Hu X, Ecelbarger CA: Sex and body-type interactions in the regulation of renal sodium transporter levels, urinary excretion, and activity in lean and obese Zucker rats. Gend Med 2006, 3(4):309-327.

16. Pedersen EB, Eiskjaer H, Madsen B, Danielsen H, Egeblad M, Nielsen CB: Effect of captopril on renal extraction of renin, angiotensin II, atrial natriuretic peptide and vasopressin, and renal vein renin ratio in patients with arterial hypertension and unilateral renal artery disease. Nephrol Dial Transplant 1993, 8(10):1064-1070.

17. Pedersen RS, Bentzen H, Bech JN, Pedersen EB: Effect of water deprivation and hypertonic saline infusion on urinary AQP2 excretion in healthy humans. Am J Physiol Renal Physiol 2001, 280(5):F860-F867.
18. Graffe CC, Bech JN, Pedersen EB: Effect of high and low sodium intake on urinary aquaporin-2 excretion in healthy humans. Am J Physiol Renal Physiol 2012, 302(2):F264-F275.

19. Lauridsen TG, Vase H, Starklint J, Bech JN, Pedersen EB: Protein-enriched diet increases water absorption via the aquaporin-2 water channels in healthy humans. Nephrol Dial Transplant 2010, 25(8):2502-2510.

20. Matthesen SK, Larsen T, Vase H, Lauridsen TG, Jensen JM, Pedersen EB: Effect of amiloride and spironolactone on renal tubular function and central blood pressure in patients with arterial hypertension during baseline conditions and after furosemide: a double-blinded, randomized, placebo-controlled crossover trial. Clin Exp Hypertens 2013, 35(5):313-324.

21. Hager H, Kwon TH, Vinnikova AK, Masilamani S, Brooks HL, Frokiaer J, Knepper MA, Nielsen S: Immunocytochemical and immunoelectron microscopic localization of alpha-, beta-, and gamma-ENaC in rat kidney. Am J Physiol Renal Physiol 2001, 280(6):F1093-F1106.

22. Pedersen RS, Bentzen $\mathrm{H}$, Bech JN, Nyvad O, Pedersen EB: Urinary aquaporin-2 in healthy humans and patients with liver cirrhosis and chronic heart failure during baseline conditions and after acute water load. Kidney Int 2003, 63(4):1417-1425.

23. Graffe CC, Bech JN, Lauridsen TG, Vase H, Pedersen EB: Abnormal increase in urinary aquaporin-2 excretion in response to hypertonic saline in essential hypertension. BMC Nephrol 2012, 13:15.

24. Graffe CC, Bech JN, Lauridsen TG, Pedersen EB: Urinary excretion of AQP2 and $\mathrm{ENaC}$ in autosomal dominant polycystic kidney disease during basal conditions and after a hypertonic saline infusion. Am J Physiol Renal Physiol 2012, 302(8):F917-F927.

25. Lauridsen TG, Vase H, Bech JN, Nielsen S, Pedersen EB: Direct effect of methylprednisolone on renal sodium and water transport via the principal cells in the kidney. Eur J Endocrinol 2010, 162(5):961-969.

26. Pisitkun T, Shen RF, Knepper MA: Identification and proteomic profiling of exosomes in human urine. Proc Natl Acad Sci U S A 2004, 101(36):13368-13373.

27. Wen H, Frokiaer J, Kwon TH, Nielsen S: Urinary excretion of aquaporin-2 in rat is mediated by a vasopressin-dependent apical pathway. J Am Soc Nephrol 1999, 10(7):1416-1429.

28. van der Lubbe N, Jansen PM, Salih M, Fenton RA, van den Meiracker AH, Danser AH, Zietse R, Hoorn EJ: The phosphorylated sodium chloride cotransporter in urinary exosomes is superior to prostasin as a marker for aldosteronism. Hypertension 2012, 60(3):741-748.

29. Isobe K, Mori T, Asano T, Kawaguchi H, Nonoyama S, Kumagai N, Kamada F, Morimoto T, Hayashi M, Sohara E, Rai T, Sasaki S, Uchida S: Development of enzyme-linked immunosorbent assays for urinary thiazide-sensitive $\mathrm{Na}-\mathrm{Cl}$ cotransporter (NCC) measurement. Am J Physiol Renal Physiol 2013, 305(9):F1374.

30. Butterworth MB, Edinger RS, Frizzell RA, Johnson JP: Regulation of the epithelial sodium channel by membrane trafficking. Am J Physiol Renal Physiol 2009, 296(1):F10-F24

31. Gimenez I, Forbush B: Short-term stimulation of the renal Na-K-Cl cotransporter (NKCC2) by vasopressin involves phosphorylation and membrane translocation of the protein. J Biol Chem 2003, 278(29):26946-26951.

32. Sands JM, Layton HE: The physiology of urinary concentration: an update. Semin Nephrol 2009, 29(3):178-195.

33. Knepper MA, Brooks HL: Regulation of the sodium transporters NHE3, NKCC2 and NCC in the kidney. Curr Opin Nephrol Hypertens 2001, 10(5):655-659.

34. Kim GH, Ecelbarger CA, Mitchell C, Packer RK, Wade JB, Knepper MA: Vasopressin increases $\mathrm{Na}-\mathrm{K}-2 \mathrm{Cl}$ cotransporter expression in thick ascending limb of Henle's loop. Am J Physiol 1999, 276(1 Pt 2):F96-F103.

35. Rieg T, Tang T, Uchida S, Hammond HK, Fenton RA, Vallon V: Adenylyl cyclase 6 enhances NKCC2 expression and mediates vasopressininduced phosphorylation of NKCC2 and NCC. Am J Pathol 2013, 182(1):96-106

36. Ortiz PA: CAMP increases surface expression of NKCC2 in rat thick ascending limbs: role of VAMP. Am J Physiol Renal Physiol 2006, 290(3):F608-F616.

37. Simon DB, Karet FE, Hamdan JM, DiPietro A, Sanjad SA, Lifton RP: Bartter's syndrome, hypokalaemic alkalosis with hypercalciuria, is caused by mutations in the Na-K-2Cl cotransporter NKCC2. Nat Genet 1996, 13(2):183-188

38. Jensen JM, Mose FH, Bech JN, Nielsen S, Pedersen EB: Effect of volume expansion with hypertonic- and isotonic saline and isotonic glucose on 
sodium and water transport in the principal cells in the kidney. BMC Nephrol 2013, 14(1):202.

39. Nakamura T, Saito T, Kusaka I, Higashiyama M, Nagasaka S, Ishibashi S, Ishikawa SE: Decrease in urinary excretion of aquaporin-2 associated with impaired urinary concentrating ability in diabetic nephropathy. Nephron 2002, 92(2):445-448.

40. Wilson DR, Sonnenberg H: Medullary collecting duct function in the remnant kidney before and after volume expansion. Kidney Int 1979, 15(5):487-501.

41. Jawadi MH, Ho LS, Dipette D, Ross DL: Regulation of plasma arginine vasopressin in patients with chronic renal failure maintained on hemodialysis. Am J Nephrol 1986, 6(3):175-181.

42. Bouby N, Bachmann S, Bichet D, Bankir L: Effect of water intake on the progression of chronic renal failure in the $5 / 6$ nephrectomized rat. Am J Physiol 1990, 258(4 Pt 2):F973-F979.

43. Ecelbarger CA, Nielsen S, Olson BR, Murase T, Baker EA, Knepper MA, Verbalis JG: Role of renal aquaporins in escape from vasopressin-induced antidiuresis in rat. J Clin Invest 1997, 99(8):1852-1863.

44. Kwon TH, Frokiaer J, Knepper MA, Nielsen S: Reduced AQP1, -2, and -3 levels in kidneys of rats with CRF induced by surgical reduction in renal mass. Am J Physiol 1998, 275(5 Pt 2):F724-F741.

45. Teitelbaum I, McGuinness S: Vasopressin resistance in chronic renal failure Evidence for the role of decreased V2 receptor mRNA. J Clin Invest 1995, 96(1):378-385.

46. Loffing J, Korbmacher C: Regulated sodium transport in the renal connecting tubule (CNT) via the epithelial sodium channel $(\mathrm{ENaC})$. Pflugers Arch 2009, 458(1):111-135.

47. Greene EL, Kren S, Hostetter TH: Role of aldosterone in the remnant kidney model in the rat. J Clin Invest 1996, 98(4):1063-1068.

48. Berl T, Katz FH, Henrich WL, de Torrente A, Schrier RW: Role of aldosterone in the control of sodium excretion in patients with advanced chronic renal failure. Kidney Int 1978, 14(3):228-235.

49. Hene RJ, Boer P, Koomans HA, Mees EJ: Plasma aldosterone concentrations in chronic renal disease. Kidney Int 1982, 21(1):98-101.

50. Masilamani S, Kim GH, Mitchell C, Wade JB, Knepper MA: Aldosteronemediated regulation of $\mathrm{ENaC}$ alpha, beta, and gamma subunit proteins in rat kidney. J Clin Invest 1999, 104(7):R19-R23.

51. Moissl UM, Wabel P, Chamney PW, Bosaeus I, Levin NW, Bosy-Westphal A, Korth O, Muller MJ, Ellegard L, Malmros V, Kaitwatcharachai C, Kuhlmann MK, Zhu F, Fuller NJ: Body fluid volume determination via body composition spectroscopy in health and disease. Physiol Meas 2006, 27(9):921-933

52. Brennan BL, Yasumura S, Letteri JM, Cohn SH: Total body electrolyte composition and distribution of body water in uremia. Kidney Int 1980 17(3):364-371

53. Verdalles U, de Vinuesa SG, Goicoechea M, Quiroga B, Reque J, Panizo N, Arroyo D, Luno J: Utility of bioimpedance spectroscopy (BIS) in the management of refractory hypertension in patients with chronic kidney disease (CKD). Nephrol Dial Transplant 2012, 27(Suppl 4):iv31-5.

doi:10.1186/1471-2369-15-101

Cite this article as: Jensen et al: Abnormal urinary excretion of NKCC2 and AQP2 in response to hypertonic saline in chronic kidney disease: an intervention study in patients with chronic kidney disease and healthy controls. BMC Nephrology 2014 15:101.

\section{Submit your next manuscript to BioMed Central and take full advantage of:}

- Convenient online submission

- Thorough peer review

- No space constraints or color figure charges

- Immediate publication on acceptance

- Inclusion in PubMed, CAS, Scopus and Google Scholar

- Research which is freely available for redistribution 